\title{
A Biomimetic Total Synthesis of the Pentacyclic Amaryllidaceae Alkaloid Derivative Gracilamine
}

\author{
Nadia (Yuqian) Gao, Martin G. Banwell ${ }^{*}$ and Anthony C. Willis
}

Research School of Chemistry, Institute of Advanced Studies

The Australian National University, Canberra, ACT 2601, Australia. Supporting Information Placeholder

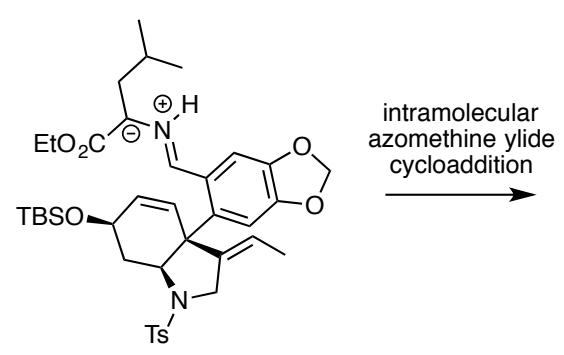

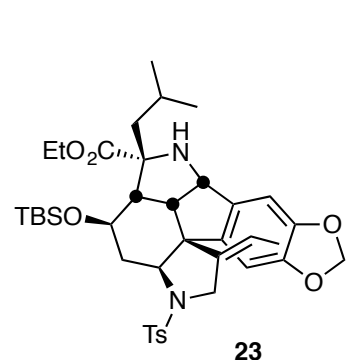

23

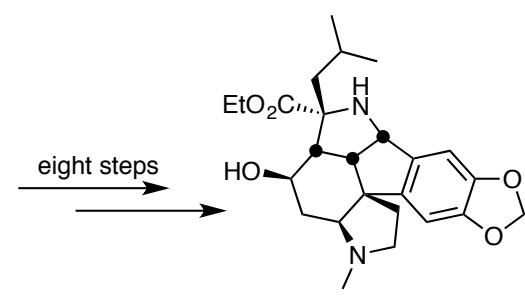

$( \pm)-1$

$[( \pm)$-gracilamine $]$

ABSTRACT: The illustrated azomethine ylide, produced through a Schiff base condensation of the corresponding aldehyde-containing C3aarylhexahydroindole with ethyl $L$-leucinate, engages in a stereoselective intramolecular cycloaddition reaction to give adduct $\mathbf{2 3}$ that has been elaborated, over eight steps, into the racemic modification of the alkaloid derivative gracilamine (1). The formation of this ylide and its conversion into isomer $\mathbf{2 3}$ mimics the proposed biogenesis of the pentacyclic framework of compound $\mathbf{1}$.

In 2005 Ünver and Kaya reported ${ }^{1}$ that ethanolic extraction of the dried and powdered total plant material derived from Galanthus gracilis, a Turkish member of the Amaryllidaceae family, lead to the isolation of gracilamine and to which the unprecedented structure 1 (Figure 1) was assigned on the basis of extensive NMR spectroscopic and mass spectrometric analyses. The, at that time, undefined configuration of the hydroxyl group followed from the first total synthesis of gracilamine. ${ }^{2}$ The ethyl ester moiety associated with compound $\mathbf{1}$ is almost certainly an artifact of the isolation process, the naturally occurring alkaloid presumably being either another ester or the corresponding free acid. A reaction sequence that mimics the proposed ${ }^{1}$ biogenesis of the pentacyclic ABCDEframework of gracilamine and that could, in principle, be used to generate this target is shown Figure 1. This involves an intramolecular $[3+2]$ cycloaddition reaction of the unsaturated azomethine ylide 2 that might itself be generated through a Schiff base condensation reaction between the aldehyde 3 (containing an embedded C3a-arylated hexahydroindole moiety) and ethyl leucinate (4). ${ }^{3}$

The validity of the approach to gracilamine defined above is supported by the elegant work of $\mathrm{Ma}$ and co-workers ${ }^{2}$ who, in 2012, reported that a spiro-ring fused cyclohexa-1,4-diene containing a tethered Schiff-base could be engaged in a thermally-induced and stereoselective intramolecular [3+2] cycloaddition reaction and so giving a product that incorporates the ABDE-ring system of gracilamine. An intramolecular hetero-Michael addition reaction was then used to establish the C-ring and a stereoselective reduction of an E-ring ketone carbonyl group then used to introduce the required $\beta$-configured hydroxyl group of $( \pm)$-gracilamine, the structure of which was confirmed by single-crystal X-ray analysis.

In $2014 \mathrm{Gao}$ and co-workers detailed ${ }^{4}$ an $\mathrm{AE} \rightarrow \mathrm{AEB} \rightarrow \mathrm{AEBC}$ $\rightarrow$ AEBCD ring-assembly process involving photo-Nazarov, intramolecular hetero-Michael and intramolecular Mannich reactions as key events in their synthesis of $( \pm)$-gracilamine. They, too, confirmed the structure of compound $( \pm)-1$ by single-crystal X-ray analysis.

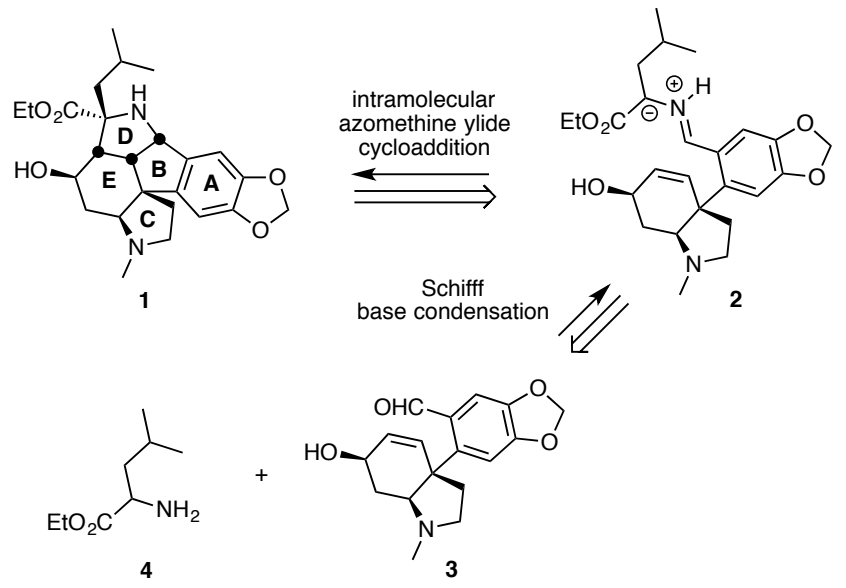

Figure 1: The structure of gracilamine (1) and a potentially biomimetic pathway for its synthesis using an intramolecular azomethine ylide cycloaddition reaction

In 2015 Adrio and co-workers reported ${ }^{5}$ a rather concise synthesis of a $1,2,3,3 a, 4,8 b$-hexahydroindeno $[1,2-b]$ pyrrole that embodies key elements of the ABD-core of gracilamine. A formal total synthesis of the title compound was subsequently realized by $\mathrm{Yu}$ and co-workers ${ }^{6}$ who assembled, in an enantioselective fashion using a $\mathrm{Rh}(\mathrm{I})$-catalyzed $[3+2+1]$ cycloaddition reaction, an AEBcontaining system associated with Gao's synthesis. Finally, and very recently, Snyder and co-workers detailed ${ }^{7}$ a pyrone-based intramo- 
lecular Diels-Alder route to a methylene-bridged C3a-arylated hexahydroindole containing the AEBC-framework of ( \pm )-gracilamine and that could be elaborated to an advanced intermediate associated with Gao's total synthesis.

We have reported ${ }^{8}$ that the $\mathrm{Pd}(\mathrm{II})$-catalysed intramolecular Alder-ene (IMAE) reaction of propargylated 1-amino-2-aryl-2cyclohexenes allows for the ready generation of C3a-arylated hexahydroindoles and subsequently deployed this and closely related processes in the synthesis of a range of natural products and natural product scaffolds. ${ }^{9}$ Accordingly, we sought to use such a process for preparing compounds related to compound 3 (Figure 1) in order to further probe the validity of the proposed biogenesis of the gracilamine framework. The preparation of a suitable C3aarylhexahydroindole is shown in Scheme 1 and began with the conversion of the readily available 2 -iodocyclohex-2-en-1-ol $(5)^{10}$ into the corresponding mesylate under the Crossland-Servis conditions. ${ }^{11}$

Scheme 1: Synthesis of the Aldehyde-containing C3a-Arylated Hexahydroindole 12

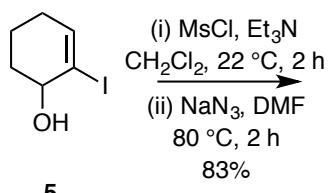

5

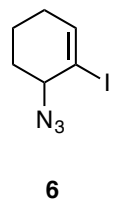

(i) $\mathrm{Ph}_{3} \mathrm{P}$, water $\mathrm{MeOH}, 22^{\circ} \mathrm{C}, 1 \mathrm{~h}$

(ii) $\mathrm{NsCl}$ $\mathrm{Et}_{3} \mathrm{~N}, \mathrm{CH}_{2} \mathrm{Cl}_{2}$ $0^{\circ} \mathrm{C}, 2 \mathrm{~h}, 82 \%$ $\mathrm{Ns}^{-} \mathrm{N}_{-} \mathrm{H}$ 7 $\mathrm{PdCl}_{2} \mathrm{dppf} \cdot \mathrm{CH}_{2} \mathrm{Cl}_{2}$ $\mathrm{Et}_{3} \mathrm{~N}$, water, THF<smiles>CC(=O)c1cc2c(cc1C1=CCCCC1NS(C)(=O)=O)OCO2</smiles>

9 $\mid \begin{gathered}\mathrm{NaH}, \mathrm{DMF} \\ 0{ }^{\circ} \mathrm{C}, 1.5 \mathrm{~h} \text { then } \\ 1 \text {-bromo-2-butyne } \\ 0 \text { to } 18^{\circ} \mathrm{C}, 2 \mathrm{~h}, 87 \%\end{gathered}$

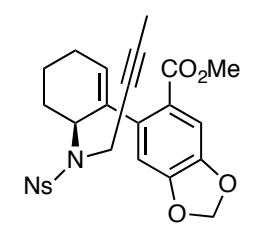

10

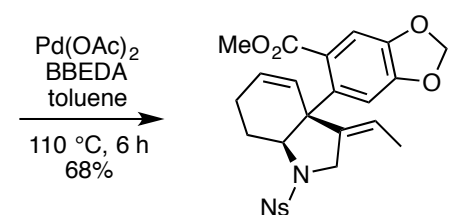

$\mathrm{Ns}$<smiles>CC(=O)c1cc2c(cc1B1OCC(C)(C)CO1)OCO2</smiles>

8

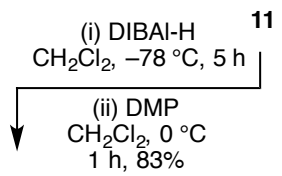<smiles>C/C=C1\CN(S(C)(=O)=O)[C@@H]2CCC=C[C@]12c1cc2c(cc1C=O)OCO2</smiles>

The product ester reacted with sodium azide in DMF to give compound $6(83 \%)$. Staudinger reduction of azide 6 and treatment of the ensuing amine with nosyl chloride $(\mathrm{NsCl})$ then gave sulfonamide 7 (82\%) that was engaged in a Suzuki-Miyaura cross-coupling reaction with arylboronate $\mathbf{8}^{12}$ to give the previously reported ${ }^{8 \mathrm{z}}$ and arylated cyclohexene 9 in $79 \%$ yield. $\mathrm{N}$-Propargylation of the anion derived from compound 9 using 1-bromo-2-butyne afforded the 1,6-enyne $\mathbf{1 0}^{8_{a}}(87 \%)$ that participated in the hoped-for and palladium-catalyzed IMAE reaction to give the hexahydroindole $\mathbf{1 1}^{\mathrm{sa}}$ (68\%). DIBAl-H-mediated reduction of ester $\mathbf{1 1}$ then gave the corresponding alcohol that was immediately converted into the target aldehyde 12 (83\%) on treatment with the Dess-Martin periodinane (DMP). All of the spectral data acquired on compound $\mathbf{1 2}$ were consistent with the assigned structure but this was finally confirmed by a single-crystal X-ray analysis, details of which are provided in the Supporting Information (SI).

The examination of the foreshadowed and pivotal intramolecular azomethine ylide cycloaddition reaction began by treating aldehyde 12 (Scheme 2) with ethyl L-leucinate in the presence of triethylamine and magnesium sulfate at ambient temperatures. The ensuing imine 13 was isolated then immediately subjected to thermolysis in refluxing toluene. By such means the regio-isomeric, crystalline and chromatographically separable $[3+2]$ cycloadducts $14(32 \%)$ and $15(36 \%)$ were obtained and the structure of each was established by single-crystal X-ray analysis (see SI for details). The former adduct clearly arises from addition of the ylide to the exocyclic olefinic residue within compound $\mathbf{1 3}$ while the latter derives from analogous addition to the cyclohexenyl double bond.

Scheme 2: Testing the Pivotal Intramolecular [3+2]Cycloaddition Reaction

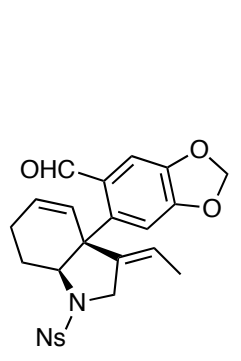

12

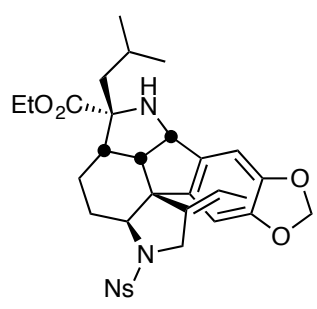

15

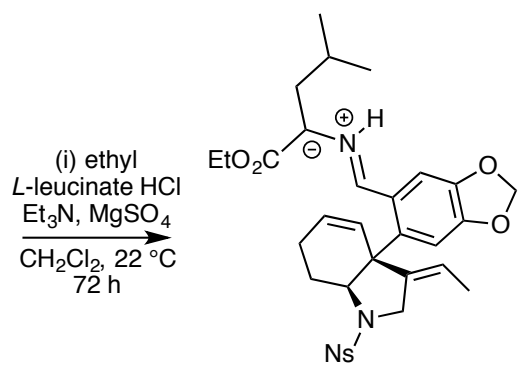

13

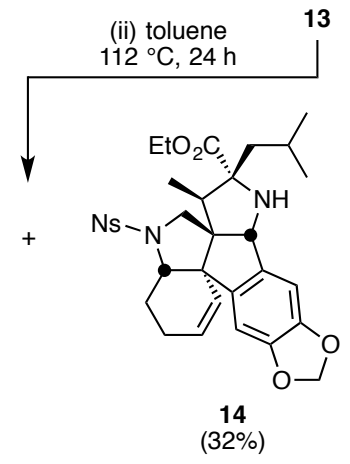

The presence of an exocyclic double bond within C3aarylhexahydroindoles prepared by the route just described is an inevitable consequence of the use of the IMAE reaction to prepare such systems ${ }^{8 b}$ and the model study clearly indicates that it participates in $[3+2]$ cycloaddition reactions when the ylide is appended to the C3a aryl unit. Based on such observations, the excision of this group as well as the introduction of the E-ring hydroxyl group of 
gracilamine became the major concerns of the campaign to reach this alkaloidal target.

The synthesis of a C3a-arylhexahydroindole carrying an E-ring hydroxyl group and potentially suitable for elaboration to gracilamine is shown in Scheme 3. Thus, the previously reported ${ }^{9 a} 6,6-$ dibromobicyclo[3.1.0] hexan-3-ol derivative 16 was converted, by established methods, ${ }^{9 a}$ into the Ts- $N$-protected allylic amine $\mathbf{1 7}$ (76\%). Suzuki-Miyaura cross-coupling of this last compound with boronate ester $\mathbf{8}$ gave the corresponding arylated cyclohexene $\mathbf{1 8}$ (83\%) and this was, in turn, engaged in an $\mathrm{N}$-propargylation reaction of the same type as used in the model study. By such means the $\mathrm{N}$-linked 1,6-enynes 19 (89\%) was obtained.

Scheme 3: Synthesis of the C3a-Arylhexahydroindole 20 Bearing an E-Ring Hydroxyl Group

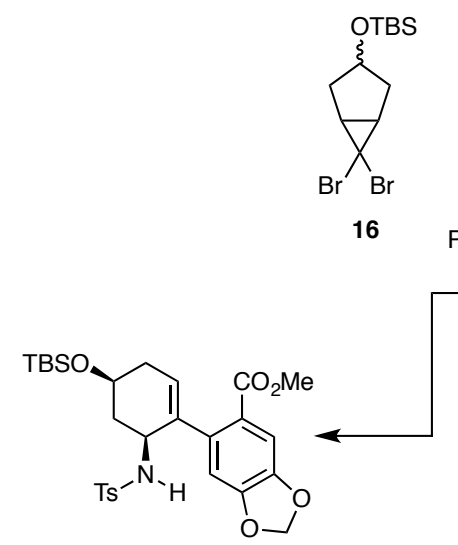

18

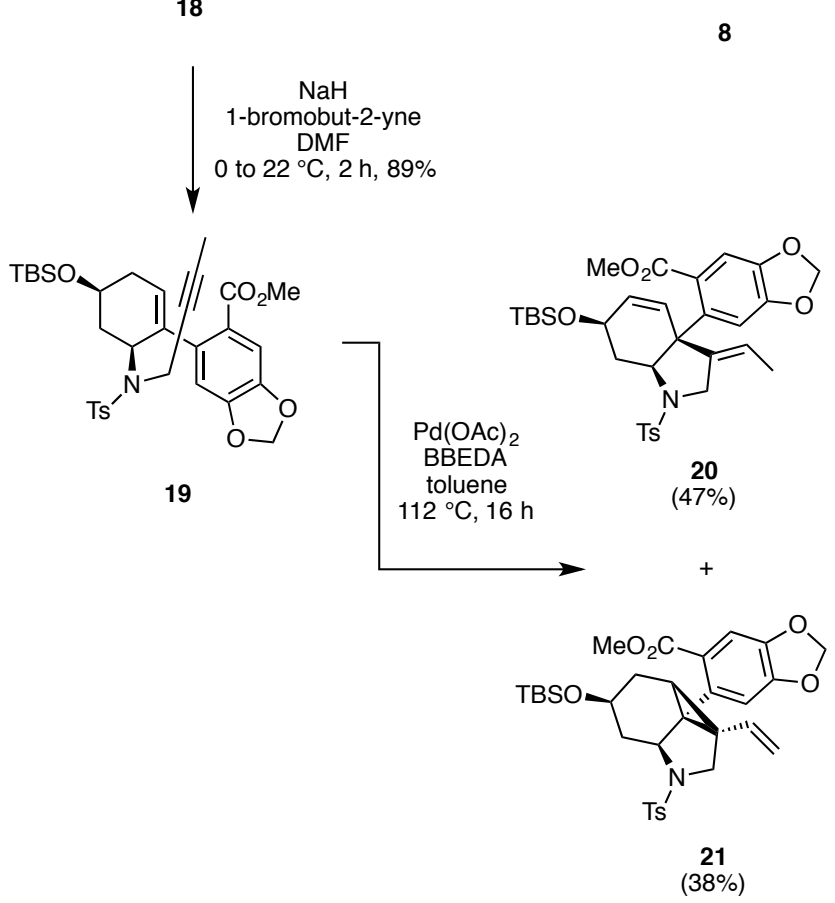

Compound 19 could be engaged in the required IMAE reaction on exposure to $\mathrm{Pd}(\mathrm{OAc})_{2}$ and $\mathrm{BBEDA}$ in refluxing toluene and so forming the C3a-arylhexahydroindole $\mathbf{2 0}$ (47\%). However, this was accompanied by its cyclopropannulated isomer 21 (38\%), the structure of which was confirmed by single-crystal X-ray analysis (see SI for details).
With compound 20 to hand some preliminary investigations on the removal of the associated exocyclic olefin moiety were undertaken. While this could be selectively oxidized with some degree of regioselectivity to give the corresponding ketone, upon reducing this to the associated alcohol it immediately engaged in a lactonization reaction with the pendant ester residue. Given such observations, sulfonamide $\mathbf{2 0}$ was carried forward toward gracilamine by employing the reaction pathway shown in Scheme 4. So, as before, the ester residue within compound $\mathbf{2 0}$ was converted, over two steps, into aldehyde $\mathbf{2 2}$ (87\%) that was then reacted with ethyl $L$ leucinate to give the expected Schiff base. Without exhaustive characterization, this was subjected to thermolysis in refluxing toluene and, as a result, the anticipated and chromatographically separable $[3+2]$ cycloadducts $23(38 \%)$ and 24 (36\%) were obtained.

Scheme 4: Synthesis of Aldehyde 22 and its Engagement in a Schiff Base Condensation/[3+2]Cycloaddition Reaction Sequence Leading to Compound 24
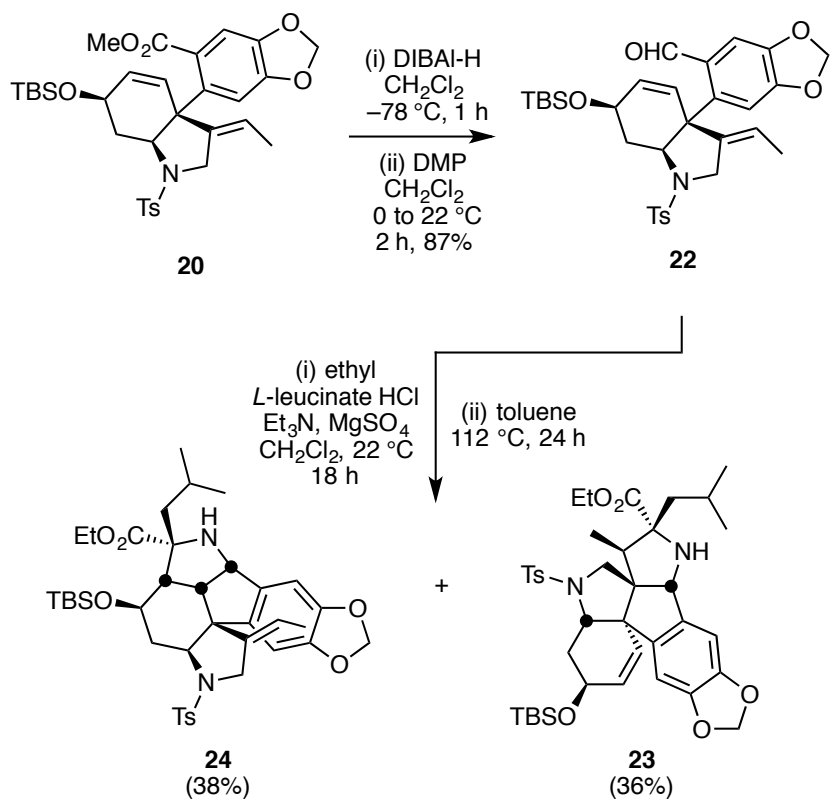

Compound 24 embodies the full pentacyclic ring system of gracilamine and its ready elaboration to the latter is shown in Scheme 5. Thus, the exocyclic olefinic residue within cycloadduct $\mathbf{2 4}$ was readily converted into the corresponding ketone $\mathbf{2 5}$ (79\%) through successive dihydroxylation and iodosylbenzene diacetatemediated oxidative cleavage. ${ }^{9 a}$ Product ketone $\mathbf{2 5}$ was then reduced, in a stereoselective manner, to the alcohol 26 (89\%) using sodium borohydride in methanol and this was itself converted into the methyl xanthate (under standard conditions) that was subjected to Barton-McCombie deoxygenation using tri- $n$-butyltin hydride and so affording the desired perhydroindole 27 (68\%). Cleavage of the sulfonamide residue associated with compound $\mathbf{2 7}$ was readily accomplished using magnesium in methanol and subjection of the amine so-formed to reaction with $3 \mathrm{M}$ aqueous hydrochloric acid resulted in cleavage of the TBS-ether and thus generating norgracilamine $\mathbf{2 8}$ in $\mathbf{7 5 \%}$ yield. Eschweiler-Clarke-type methylation of compound $\mathbf{2 8}$ using formaldehyde and sodium cyanoborohydride then gave $( \pm)$-gracilamine $[( \pm)$-1 $]$ itself in $63 \%$ yield. The structures of compounds 25, 26 and ( \pm )-1 not only follow from the derived NMR, MS and IR spectral data but also 
from the single-crystal X-ray analyses of each of these. In addition, all of the ${ }^{1} \mathrm{H}$ and ${ }^{13} \mathrm{C}$ NMR data obtained on synthetically-derived $( \pm)$-gracilamine compare favorably (see the SI for some tabulated comparisons) with those reported by both $\mathrm{Ma}^{2}$ and $\mathrm{Gao}^{4}$ for their materials and with those reported by Ünver and Kaya ${ }^{1}$ for the naturally-derived compound.

Scheme 5: Completion of the Synthesis of $( \pm)$-Gracilamine $[( \pm)$ 1]

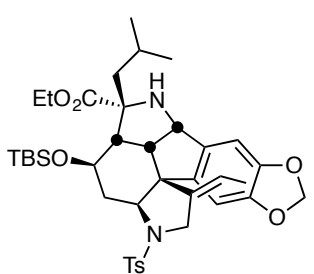

24

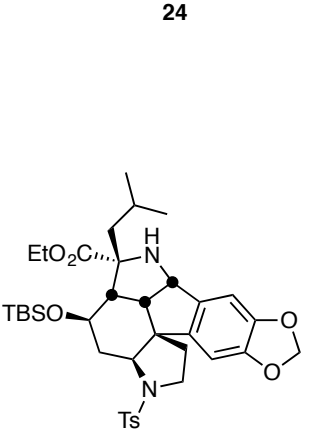

27

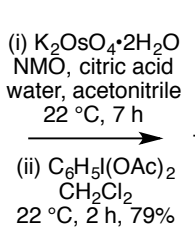

$22{ }^{\circ} \mathrm{C}, 2 \mathrm{~h}, 79 \%$

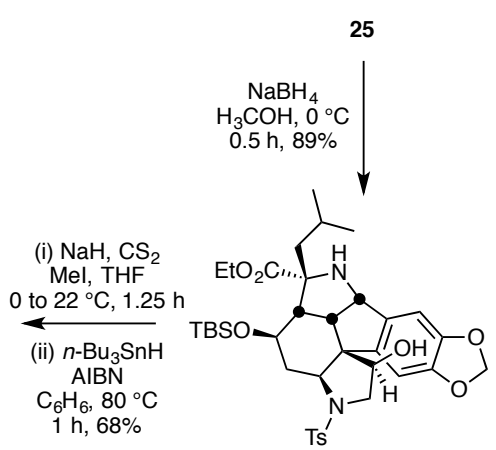

$$
\begin{gathered}
\text { (i) } \mathrm{Mg}, \mathrm{H}_{3} \mathrm{COH} \\
\text { sonication, } 22{ }^{\circ} \mathrm{C} \\
0.5 \mathrm{~h} \\
\text { (ii) } 3 \mathrm{M} \mathrm{aq} \mathrm{HCl} \\
22^{\circ} \mathrm{C}, 0.25 \mathrm{~h} \\
75 \%
\end{gathered}
$$

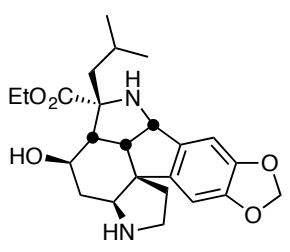

28
26
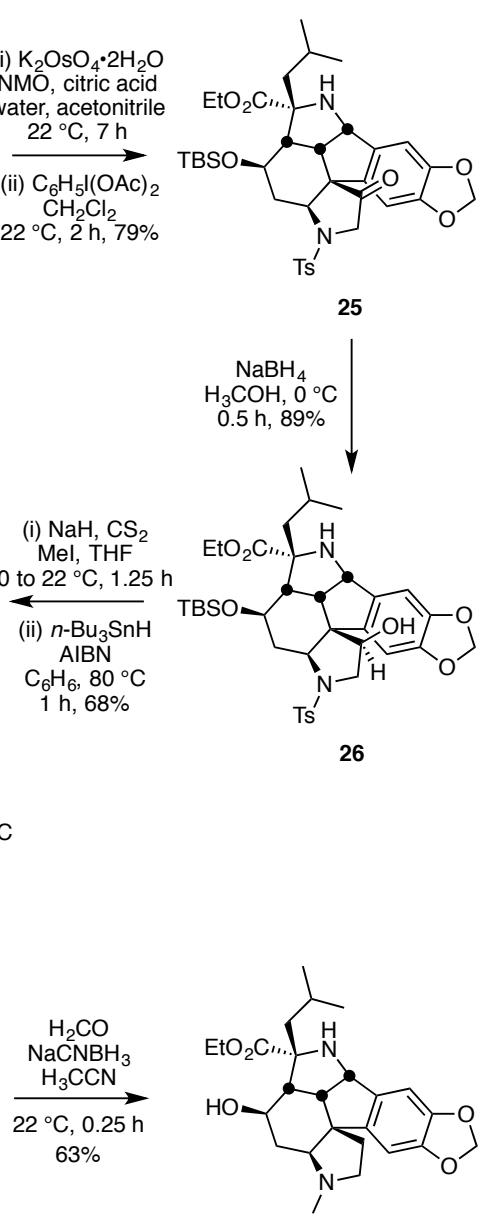

$( \pm)-1$

\section{ASSOCIATED CONTENT}

\section{Supporting Information}

Experimental procedures, spectroscopic and analytical data, copies of the NMR spectra of new compounds, and X-ray plots and data for compounds 12, 14, 15, 21, 25, 26 and ( \pm )-1. The Supporting Information is available free-of-charge on the ACS Publications website at DOI: 10.10-21/acs.orglett.XXXXXX.

\section{Corresponding Author}

*E-mail: Martin.Banwell@anu.edu.au

\section{Author Contributions}

The manuscript was written through contributions of all authors. All authors have given approval to the final version of the manuscript.

\section{Notes}

The authors declare no competing financial interest.

\section{ACKNOWLEDGEMENT}

We thank the Australian Research Council and the Institute of Advanced Studies for financial support. N(Y)G is the grateful recipient of a Post-graduate Award provided by the ANU. Dr Benoit Bolte (ANU) is warmly thanked for his invaluable advice throughout the duration of this project.

\section{REFERENCES}

1. Ünver, N.; Kaya, G. I. Turk. J. Chem., 2005, 29, 547.

2. Tain, S.; Zi, W.; Ma, D. Angew. Chem. Int. Ed., 2012, 51, 10141.

3. For useful points of entry into the literature on such cycloaddition processes, see: (a) Coldham, I.; Hufton, R. Chem. Rev., 2005, 105, 2765; (b) Nair, V.; Suja, T. D., Tetrahedron, 2007, 63, 12247; (c) Burrell, A. J. M.; Coldham, I. Curr. Org. Synth., 2010, 7, 312; (d) Vidadala, S. R.; Golz, C.; Strohmann, C.; Daniliuc, C.-G.; Waldmann, H. Angew. Chem. Int. Ed., 2015, 54, 651. (e) Hashimoto, T.; Maruoka, K. Chem. Rev., 2015, $115,5366$.

4. Shi, Y.; Yang, B.; Cai, S.; Gao, S. Angew. Chem. Int. Ed., 2014, 53, 9539 .

5. González-Esguevillas, Pascual-Escudero, A.; Adrio, J.; Carretero, J. C. Chem. Eur. J., 2015, 21, 4561.

6. Bose, S.; Yang, J.; Yu, Z.-X. J. Org. Chem. 2016, 81, 6757.

7. Gan, P.; Smith, M. W.; Braffman, N. R.; Snyder, S. A. Angew. Chem. Int. Ed., 2016, 55, 3625.

8. (a) Lehmann, A. L.; Willis, A. C.; Banwell, M. G. Aust. J. Chem., 2010, 63, 1665. (b) For a review, see: Crisp, A. L.; Li, J.; Lan, P.; Nugent, J.; Matoušová, E.; Banwell, M. G. Aust. J. Chem., 2015, 68, 1183.

9. (a) Petit, L.; Banwell, M. G.; Willis, A. C. Org. Lett., 2011, 13, 5800. (b) Gao, N.(Y.); Ma, X.; Petit, L.; Schwartz, B. D.; Banwell, M. G.; Willis, A. C.; Cade, I. A.; Rae, A. D. Aust. J. Chem., 2013, 66, 30. (c) Nugent, J.; Matoušová, E.; Banwell, M. G. Eur. J. Org. Chem., 2015, 3771.

10. Sha, C.-K.; Huang, S.-J.; Zhan, Z.-P. J. Org. Chem., 2002, 67, 831.

11. Crossland, R. K.; Servis, K. L. J. Org. Chem., 1970, 35, 3195.

12. Schwartz, B. D.; Banwell, M. G.; Cade, I. A. Tetrahedron Lett., 2011, 52, 4526.

\section{AUTHOR INFORMATION}

